\title{
Measles elimination in Canada: Pressures to change the timeline
}

$\mathrm{W}$ HEN THE GOAL OF ELIMINATING INDIGENOUS MEASLES IN Canada was first recommended at the National Consensus Conference in 1992, the target date was set at 2005 (1). The proposed timeline included a target of 1997 to achieve and maintain $97 \%$ coverage with the first dose of vaccine by two years of age, and a target of 2000 to achieve and maintain $99 \%$ vaccine coverage with a second dose of vaccine before school entry (1). The rationale for not moving forward more quickly was based on a combination of factors. The measles rate in Canada had declined so sharply with the widespread use of the single-dose regimen that the goal of measles elimination seemed less important. Furthermore, the recognition that outbreaks could occur in school populations with documented high rates of primary immunization due to primary vaccine failures $(2,3)$ meant that a two-dose regimen would be required. It was difficult to give a high priority to this added expense when public health authorities were already scrambling to find funds to support universal school-based hepatitis $B$ vaccine programs. In addition, the second dose measles proposal had to compete against other high profile prevention programs such as those for AIDS, smoking and breast cancer. Thus, a timeline with moderate speed seemed appropriate and was accepted.

Recently, two dramatically different trends in measles prevalence in the Americas have put pressure on Canada to speed up the timeline for implementation of the two-dose program. While sporadic outbreaks have continued to occur in Canada during the past six years, even in populations with primary vaccination rates greater than $95 \%$, for example, several areas of Quebec in 1989 (2) and the Waterloo area of Ontario in 1991 (3), their continued occurrence was of increased

All material presented in Pediatric Infectious Disease Notes has been reviewed and approved by the chairperson, Canadian Paediatric Society Board and representative members of the Canadian Paediatric Society Committee on Infectious Diseases and Immunization

Correspondence and reprints: Infectious Diseases and Immunization Committee, Canadian Paediatric Society, 401 Smyth Road, Ottawa, Ontario K1H 8L1. Telephone 613-737-2728, fax 613-737-2794 concern. The 1995 measles rate in Canada $(6.1 / 100,000)$ is particularly embarrassing. The rate has been pushed up by large school outbreaks in Ontario, where the provincial rate increased to $16.3 / 100,000$ in 1995. Again, the vast majority of these cases (more than $90 \%$ ) occurred in children who were 'up to date' with their measles vaccine program, ie, had received the single dose as currently recommended. Investigating and controlling these outbreaks used substantial public health resources, and generated much public anxiety and frustration. In direct contrast to the rising rates in Canada, the rates in all other countries in the Americas (North, South and Central) have plummeted in the past two years due to aggressive campaigns to eliminate measles. Canada, which has less than $4 \%$ of the region's population, now accounts for over $78 \%$ of all reported measles cases in the Americas (4).

In order to control the measles problem more rapidly in these two large provinces, Ontario, Quebec and the Northwest Territories are moving to implement the two-dose measles vaccine program in 1996. In their new schedules, the timing of the first dose of measles, mumps and rubella vaccine is unchanged (12 months of age) and the second dose is planned to precede school entry in Ontario, while in Quebec and the Northwest Territories it will be at 18 months of age. Given Ontario's ongoing problem with measles, the Ministry of Health has also announced a mass measles vaccine program (a second dose catch-up campaign) in 1996 for children attending school to be carried out by the local public health units. The measles vaccine will be provided to each health unit but additional costs for personnel to deliver the vaccine are not included. However, the expectation is that the health units, by carrying out this mass second dose catch-up campaign, will be able to save money by not having measles outbreaks to investigate and control. While concerns have been raised that the mass catch-up program in Ontario should use the measles, mumps and rubella vaccine, rather than the measles vaccine alone, the additional costs for the trivalent vaccine would substantially increase the cost of the catch-up program and thus limit the school grades that could be covered. The plan to immunize all students in all grades with the monovalent vaccine was the chosen compromise. This 
blitz strategy is similar to the one undertaken in 1994 in England and Wales (5) and is expected to be equally successful in controlling measles. A similar mass campaign is being contemplated for Quebec and some other provinces.

There are lessons to be learned from this measles experience. While timelines for implementation of new or extended vaccine programs are heavily influenced by concurrent political and financial concerns, delays may end up costing more, both in dollars and in public frustration as well as public loss of confidence in the effectiveness of vaccine programs.

\section{REFERENCES}

1. Consensus Conference on measles. Can Commun Dis Rep 1993;19-10:72-9.

2. Buolianne N, deSerres G, Duval B, et al. Épidemie majeure de rougeole dans la région de Québec malgré une couverture vaccinale de 99\%. Can J Public Health 1991;82:189-90.

3. Wong $\mathrm{T}$, Lee-Han $\mathrm{H}$, Bell B, et al. Measles epidemic in Waterloo Region, Ontario 1990-1991. Can Dis Wkly Rep 1991;17-41:219-24.

4. Varughese P. Measles in Canada, 1995 (as of August 8). Measles Update 1995;3:2-5.

5. Ramsay M, Gay N, Miller E, et al. The epidemiology of measles in England and Wales: rationale for the 1994 national vaccination campaign. Commun Dis Rep 1994;4:R141-6.

NE MacDonald MD FRCPC University of Ottawa, Ottawa, Ontario FD Boucher MD FRCPC Laval University, Ste-Foy, Quebec 


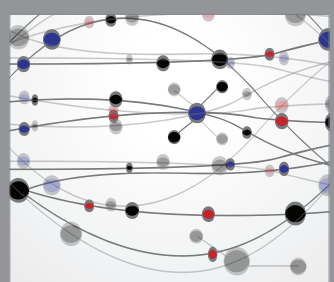

The Scientific World Journal
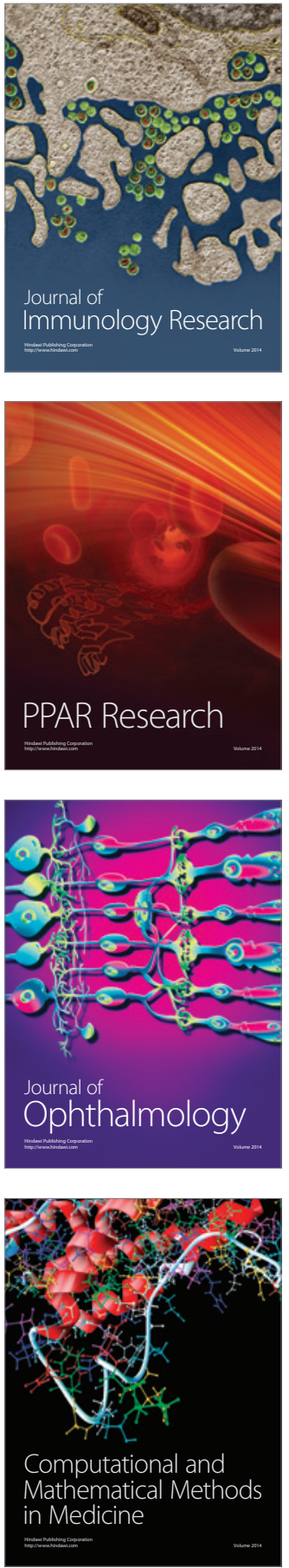

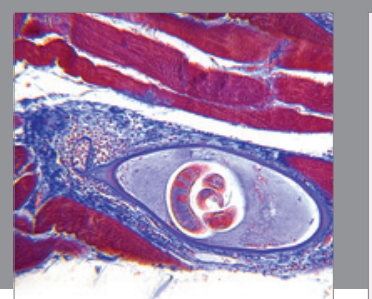

Gastroenterology Research and Practice

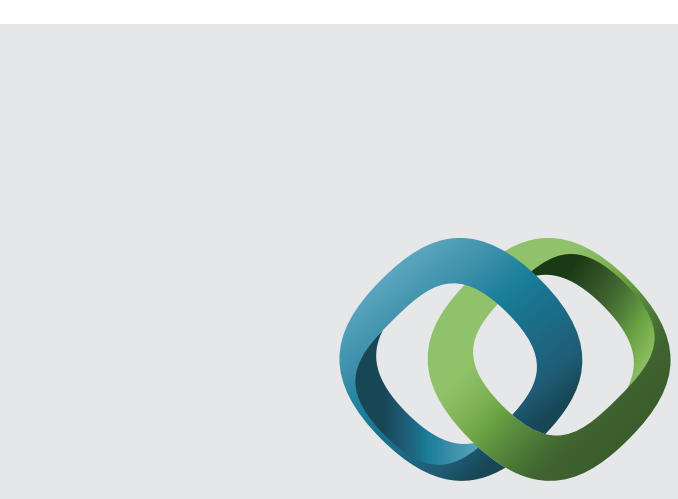

\section{Hindawi}

Submit your manuscripts at

http://www.hindawi.com
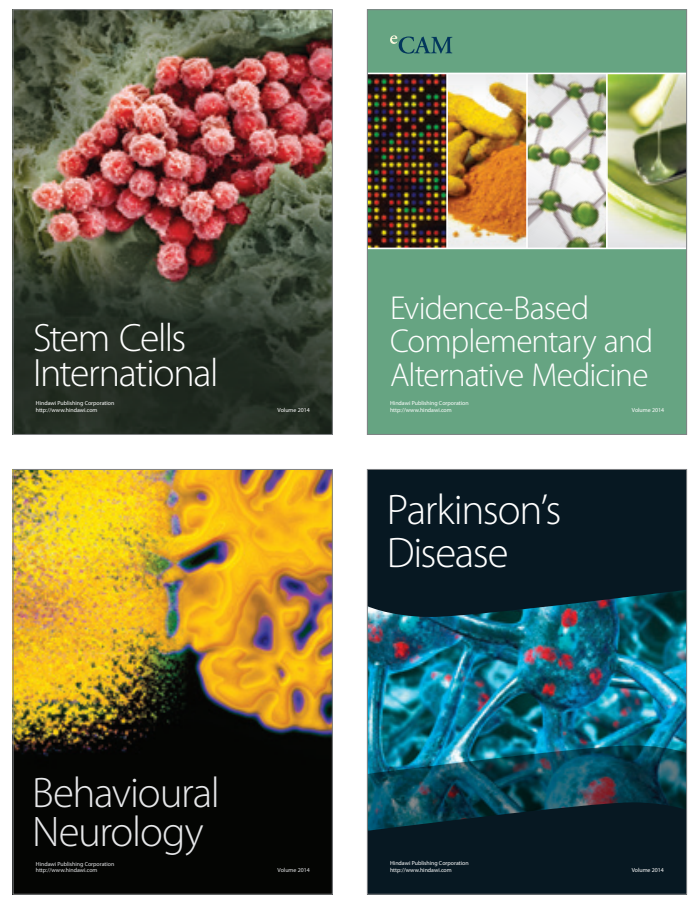
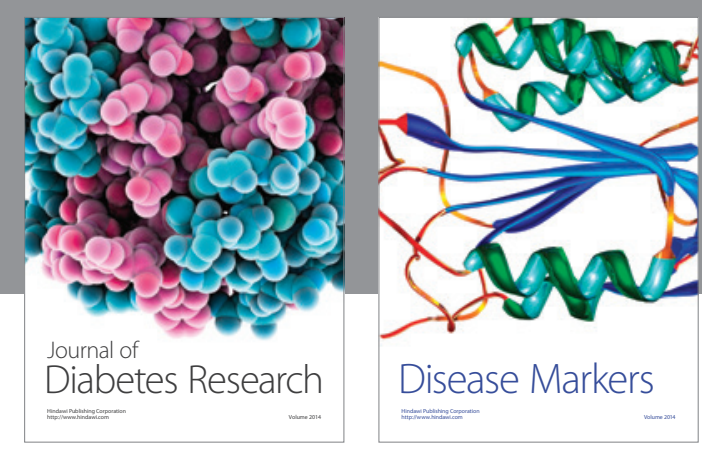

Disease Markers
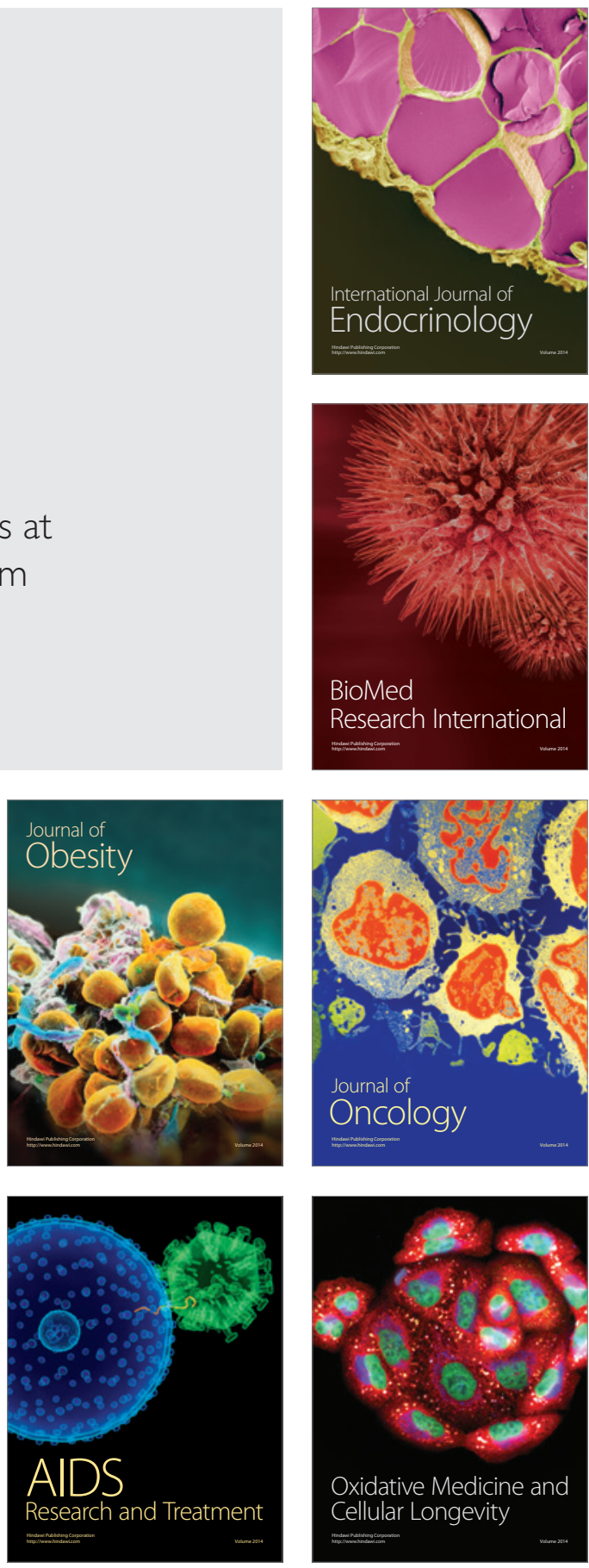